\title{
Carbon credits - reliable cash flow?
}

\author{
A.N. CROFOOT \\ Castlepoint Station, RD 9, Masterton \\ anders@castlepoint.co.nz
}

\begin{abstract}
On 27 March 2008, my wife Emily and I purchased a 737 ha property adjoining Castlepoint Station, called Mockingbird Farm. The property is typical of Wairarapa hill country ranging from small amounts of rolling hill to steep hills with about 407 ha of reverting scrub, 200 ha of average pasture and 130 ha of pine trees. This paper covers the decision process we went through in deciding to purchase the property. A key component of that decision was the ability to sell carbon credits from the pine trees to meet the carrying costs of the purchase. The paper also outlines the process we have been through attempting to sell carbon credits, and the minefield of political whim which surrounds this. The end result is that over a year later we have yet to sell any carbon credits.
\end{abstract}

\section{Introduction}

Mockingbird Farm is a coastal Wairarapa property which adjoins Castlepoint Station at its southern boundary. Mockingbird Farm is the balance of the land left after a developer bought Wai Ngaio Farm and subdivided 10 ha lifestyle blocks off the coastal frontage. The previous owner had planted 130 ha of Pinus radiata on the easier country closest to the coast. In the 10 years that we have been at Castlepoint Station, Mockingbird has had a somewhat chequered history. It had been offered for sale to us several times, the first time for $\$ 15,000,000$ (we just laughed). However, it had finally ended up in receivership and after it failed to sell at auction, we were approached again, this time with a valuation of $\$ 1,500,000$.

As a viable farm it was marginal. For practical purposes there was no internal fencing. There was no fertiliser history (soil tests in August 2008, average $\mathrm{pH}$ 5.2, Olsen P, 6). Much of the reverting scrub country faces north-west. Even if reclaimed out of scrub, it would be unlikely to become high producing pasture (less than $5 \mathrm{t} \mathrm{DM} / \mathrm{ha} / \mathrm{yr})$. The pine trees had been pruned only once (that was late), and they had never been thinned (it was getting almost too late to thin effectively). With the wind run on the Wairarapa coast, especially near Castlepoint, the trees are prone to forming resin pockets so they often do not produce high quality timber.

Still we had an interest for a number of reasons:

It was contiguous land so it could easily be incorporated into our existing operations.
The boundary with Castlepoint Station is a give and take boundary. When it was a farm to farm this boundary worked quite well. However, as subdivision took place and small-lot owners wanted all their land, re-fencing on the actual boundary was difficult.

There were several east-facing basins, similar to ones on Castlepoint Station, which we knew were protected from the north-west wind and held on well into the summer. This would give us more pasture at a critical time of year.

The soils hold more stones than do Castlepoint's and we felt they would accommodate heavy cattle during the winter without as much damage to the soil structure. We would be able to winter our cows there to protect our better developed soils.

With New Zealand's commitment to the Kyoto Protocol and the inclusion of livestock, we were looking for ways to balance our potential liabilities for livestock emissions. According to calculations based on MAF numbers, at 9-10 stock units per hectare, if about ten percent of the farm was planted in pine trees their carbon sequestration would about balance the livestock emissions. This equates to about 280 ha in trees. Castlepoint Station is 2950 ha, 2,800 in pasture and 70 ha in pine trees. The remaining 80 ha accounts for buildings, yards and laneways. To have 280 ha in pine trees we would need to plant around 200 ha of existing productive pasture into forest.

At the March 2007 PCE20 Forum: "Advancing Environmental Sustainability", held to celebrate 20 years of the Parliamentary Commissioner for the Environment, one of the speakers said "It doesn't matter what you think about climate change, enough of the world's population thinks we have a problem, therefore we have a problem. Go figure out how you are going to make a dollar out of it." Taking on board that comment with a couple of other business rules-(a) the first rule of business is to stay in business, and (b) the customer is always right- we felt rather than complaining about the hand that has been dealt us, we needed to find out how to make lemonade from the lemons.

According to the draft Climate Change Response (Emissions Trading) Amendment Act 2008, which was circulating and looked very likely to pass (passed September 2008), forestry was to be placed into the Emissions Trading Scheme (ETS). Liquid Fossil Fuels were to enter the ETS in January 2009, which would 
Carbon (C) cash flow.

\begin{tabular}{lrrrrrrrrrr}
\hline & Year 1 & Year 2 & Year 3 & Year 4 & Year 5 & Year 6 & Year 7 & Year 8 & Year 9 & Year10 \\
\hline Existing pines (age) & 12 & 13 & 14 & 15 & 16 & 17 & 18 & 19 & 20 & 21 \\
C sequestered/ha & 53.58 & 54.29 & 54.63 & 54.74 & 54.61 & 54.22 & 53.55 & 52.59 & 51.34 & 49.84 \\
\$ value (136 ha @ \$20/unit) & 145,737 & 147,682 & 148,606 & 148,881 & 148,529 & 147,472 & 145,646 & 143,031 & 139,653 & 135,568
\end{tabular}

Regenerating scrub

\begin{tabular}{|c|c|c|c|c|c|c|c|c|c|c|}
\hline C sequestered/ha & 4 & 4 & 4 & 4 & 4 & 4 & 4 & 4 & 4 & 4 \\
\hline \$ value (182 ha @ \$20/unit) & 14,560 & 14,560 & 14,560 & 14,560 & 14,560 & 14,560 & 14,560 & 14,560 & 14,560 & 14,560 \\
\hline New pine planting (age) & 1 & 2 & 3 & 4 & 5 & 6 & 7 & 8 & 9 & 10 \\
\hline $\mathrm{C}$ sequestered /ha & 0 & 0 & 0.71 & 4.14 & 9.70 & 17.59 & 26.90 & 36.15 & 43.82 & 49.08 \\
\hline \$ value (214 ha @ \$20/unit) & 0 & 0 & 3,054 & 17,735 & 41,501 & 75,288 & 115,131 & 154,705 & 187,548 & 210,064 \\
\hline \multirow[t]{2}{*}{ Total C value @ \$20/unit } & 160,297 & 162,242 & 166,220 & 181,176 & 204,591 & 237,320 & 275,337 & 312,297 & 341,761 & 360,192 \\
\hline & Year 11 & Year 12 & Year 13 & Year 14 & Year 15 & Year 16 & Year 17 & Year 18 & Year 19 & \\
\hline Existing pines (age) & 22 & 23 & 24 & 25 & 26 & 27 & 28 & 29 & 30 & \\
\hline C sequestered/ha & 48.11 & 46.18 & 44.09 & 41.87 & 39.56 & 37.19 & 34.80 & 32.40 & 30.03 & \\
\hline \$ value (136 ha@\$20/unit) & 130,855 & 125,606 & 119,916 & 113,883 & 107,604 & 101,166 & 94,654 & 88,141 & 81,693 & \\
\hline \multicolumn{11}{|l|}{ Regenerating scrub } \\
\hline C sequestered/ha & 4 & 4 & 4 & 4 & 4 & 4 & 4 & 4 & 4 & \\
\hline \$ value (182 ha @ \$20/unit) & 14560 & 14560 & 14560 & 14560 & 14560 & 14560 & 14560 & 14560 & 14560 & \\
\hline New pine planting (age) & 11 & 12 & 13 & 14 & 15 & 16 & 17 & 18 & 19 & \\
\hline C sequestered /ha & 52.08 & 53.58 & 54.29 & 54.63 & 54.74 & 54.61 & 54.22 & 53.55 & 52.59 & \\
\hline \$ value (214 ha @ \$20/unit) & 222,914 & 229,321 & 232,383 & 233,835 & 234,269 & 233,715 & 232,052 & 229,178 & 225,064 & \\
\hline Total C value @ \$20/unit & 368,329 & 369,486 & 366,858 & 362,279 & 356,433 & 349,442 & 341,266 & 331,879 & 321,317 & \\
\hline
\end{tabular}

create a ready domestic market. The International market was already well established in Europe and even in the US, carbon credits were being traded on the Chicago Exchange. We felt that although we weren't going to justify the purchase off the income from grazing livestock on 200 ha of average pasture, the sale of carbon credits from the pine trees might cast things in a different light.

\section{Methods}

Castlepoint Station already had about 70 ha of forestry. We asked our forestry consultant, Stuart Orme of Woodnet Works Ltd., to take a look at the Mockingbird Farm trees and give us an evaluation of their potential for carbon trading. Stuart came and made measurements over a limited sample area (10 plots). The trees averaged - DBH $29.08 \mathrm{~cm}$, prune height $4.7 \mathrm{~m}$, tree height 20.97 $\mathrm{m}$. Working from a table of expected growth rates for Pinus radiata and therefore expected rates of carbon sequestration, he came up with a cash-flow of the value of the carbon credits over time (until the trees were 30 years old and potentially ready for harvest).

The sequestration tables derived in this way differ somewhat from the tables currently on the MAF website, however, at the time, there was nothing else available. They ended up with about the same total volume, but the MAF tables describe a fairly straight line growth response. The expected growth tables put on more volume at a young age and then taper off. Using \$20/unit, and with the trees at 12 years old, in Year 1 the gross income from the sale of all the carbon credits produced that year would be $\$ 145,737$ (Table $1)$, which would increase to $\$ 148,881$ three years later (Year 4) and then start declining to $\$ 139,653$ at Year 9, $\$ 113,883$ at Year 14 and $\$ 81,693$ at Year 19, at which point the trees would be 30 years old and possibly ready for harvest (financial projections 18 years into the future have very little probability of having any accuracy, and we were primarily interested in the first five to 10 years). So, if the property was valued at $\$ 1,500,000$ and had a mortgage for the full amount at $10 \%$, the carrying costs would be $\$ 150,000 /$ year. The income from the 
carbon credits looked would likely cover most of the carrying costs.

Additionally, we looked at the option of fencing off the reverting scrub and letting it fully revert which potentially might collect 4 units/ha. At $\$ 20$ over 182 ha this would add an additional $\$ 14,560$ per annum. Planting the balance of 214 ha of scrub in pine trees would have an initial up-front cost of just over $\$ 400,000$. These would start producing carbon credits worth $\$ 3,054$ in Year 3, peaking at $\$ 234,269$ in Year 15, then tapering down to $\$ 225,064$ by Year 19 , which is when the existing pines will be 30 years old, where we stopped the exercise.

With those additional options included the carbon credit stream started at $\$ 160,297$, and peaked at $\$ 369,486$ in Year 12 , then tapered back to $\$ 321,317$ in Year 19. Those numbers made things look attractive. The thinking was that $\$ 20 /$ unit was probably conservative, since that was what the Government was quoting (they wouldn't want to use a higher number since it would make the costs of their policies balloon). Also, at the time there were stories about units selling for NZ\$60 in Europe. I checked on the European exchanges and the European units were selling for about NZ\$47, so $\$ 60$ was a bit suspect, but $\$ 20$ seemed possible. The tempering view showed units selling on the US exchange for about NZ\$7, but they weren't for units as highly certified as a NZU (New Zealand Unit certified by MAF and convertible to an internationally tradable AAU)

\section{Results}

We signed the loan agreement on 23 March 2008 and took over the property on 27 March and changed the name from Mockingbird back to Wai Ngaio. In April, the Labour Government decided that maybe it was not such a good idea to bring Liquid Fossil Fuels into the ETS in January 2009 as proposed, postponing it until 2011. With that decision the potential domestic market for carbon credits evaporated.

We would need to look at carbon credits on the international market. In May we started working with GreenAir Ltd., a group that brokers and markets carbon credits. Although from a farm forestry point of view we had a forest of reasonable size, from a carbon trading point of view we needed to be part of a larger grouping that could aggregate credits into blocks which are readily able to be traded. With the ETS still not passed in Parliament we were looking at the Voluntary Emission Reduction (VER) market. It would not be as high paying as NZUs which could be converted to AAUs (tradeable internationally) but any cash-flow is always good.

In November when National won the election and announced they would review the ETS, the credibility of NZUs was brought into question. Would they even exist? There was a great deal of lobbying of the Government to point out that this was not a satisfactory situation. Just before Christmas the Government made the announcement that the forestry part of the ETS would not be changing, which thankfully underpinned the NZ credits on the international market again. In March we had word that a contract was ready to be signed which included our credits. By the next afternoon when Emily went into town with our side of the documentation, the pin had been pulled on the contract due to the deteriorating world financial situation.

In March 2009, we entered both Wai Ngaio and Castlepoint Station, into the NZ Emissions Trading Registry, which was a very simple process. We also registered the blocks of forestry in the MAF database. Wai Ngaio has been approved, but we are in ongoing discussions with MAF about the eligibility of two parcels on Castlepoint Station. This has not been such a simple process. In June 2009, the deadline for registering exemptions for forest under 50 ha was pushed out indefinitely.

\section{Discussion}

There have been many changes since we purchased the property. The domestic market for carbon credits is on hold pending a review of the ETS. If the review is completed before the end of the year, then stationary energy would come into the ETS in January 2010, which would start demand in the domestic market. Liquid fossil fuels which we thought would enter the ETS in January 2009 have been postponed until January 2011. Agriculture is still likely to be included in January 2013, but who knows what form that will take (currently it will start with only $10 \%$ of emissions, building to $100 \%$ by 2020 ).

Looking back at our original analysis, despite the many changes since, it was fairly robust.

The scrub for which we thought we might get credits, given early indications from MAF that they would be eligible, now are not likely to be available for credits due to a later decision. This knocks $\$ 14,500$ off the potential cashflow.

With the string of changes that have occurred, we haven't had the confidence to plant any trees, so that part of the potential cashflow is moved further out, but so are the planting costs. There have been changes made to the Afforestation Grant Scheme, which make it quite attractive and would cover most of the costs of tree planting in return for the carbon credits generated for the first 10 years. This is also quite attractive as one of the main options for the carbon sequestered in those 214 ha was for it to be used as an offset for livestock emissions.

At this point we are only looking at potential cash- 
flow from the existing pine trees.

The price we used of $\$ 20 /$ unit is looking attractive. Although we haven't managed to complete a contract, those that have been discussed have been around \$24/ unit. A rising NZ \$ may not help that.

Another major consideration when looking at the longer time frames, is the liabilities for carbon credits at the time of tree harvest. As the rules currently stand, it is considered that one third of the carbon stays sequestered in the stump and roots of the trees at harvest and the rest of the carbon is released immediately. So one third of the carbon credits have no liability attached and the remaining two thirds of the credits will need to be repaid at whatever the going rate for carbon is at the time. This means that one third of the carbon credits generated in a forest can be sold with no liability, as long as they were sequestered within the first or subsequent commitment periods. The second two thirds of the carbon credits can be sold, but they will be liable for repayment of credits at the time of harvest. If the price of carbon is lower than when sold, you come out ahead; if it is higher, it may be costly, and you could elect not to harvest and continue to generate and sell the carbon. Pine trees actually don't stop growing at 30 years.

\section{Conclusion}

We did not pay the full asking price for the property. Interest rates have also dropped below $10 \%$, so the carrying costs have been less than the $\$ 150,000$ in our initial modelling. With the drought we have experienced since we purchased the property, the cattle grazing we have had from it has been valuable. It is not a cash return, but the value of the grazing and cost savings from not needing to truck cattle, would offset over half the interest costs.

While the market for carbon credits still seems to be sitting just over the horizon, there have been some important sales, which indicate things are settling down, and the market will appear. We have confidence that by next year, we should be getting positive cash-flow. Don't ever count on markets dominated by politics being straightforward. 